\title{
Ethics and Social Responsibility An Agenda for Interdisciplinary and International Research on Borderless Net Business Ethics
}

\author{
Amos Nascimento \\ University of Washington, Tacoma - USA \\ UNIMEP, Piracicaba - Brazil
}

\begin{abstract}
My remarks aim at presenting some basic concepts of an ethical theory that could provide a framework for discussion, cooperation, and effective partnership in international research on borderless communication, technology, and business. To develop this idea, I introduce the key ideas of discourse ethics, then characterize the work of some global and borderless organizations and networks that promote research and education, and finally discuss how communication can occur effectively within the already existing global framework of educational institutions related to IAMSCU.
\end{abstract}

\section{Introduction}

The 20th century saw the emergence of a series of technologies that were applied to information, broadcasting, and communication in general. These technologies, such as the radio, telegraph, telephone, television, fax machine, computers, and the Internet, among many others, have now shaped our societies and transformed the way by which we interact with reality as well as with ourselves both individually and collectively. The traditional and standard account of the progress and development sees this process as very positive. This image is represented by Isaac Asimov in the following chart (reproduced from Erickson, 2005: 90):

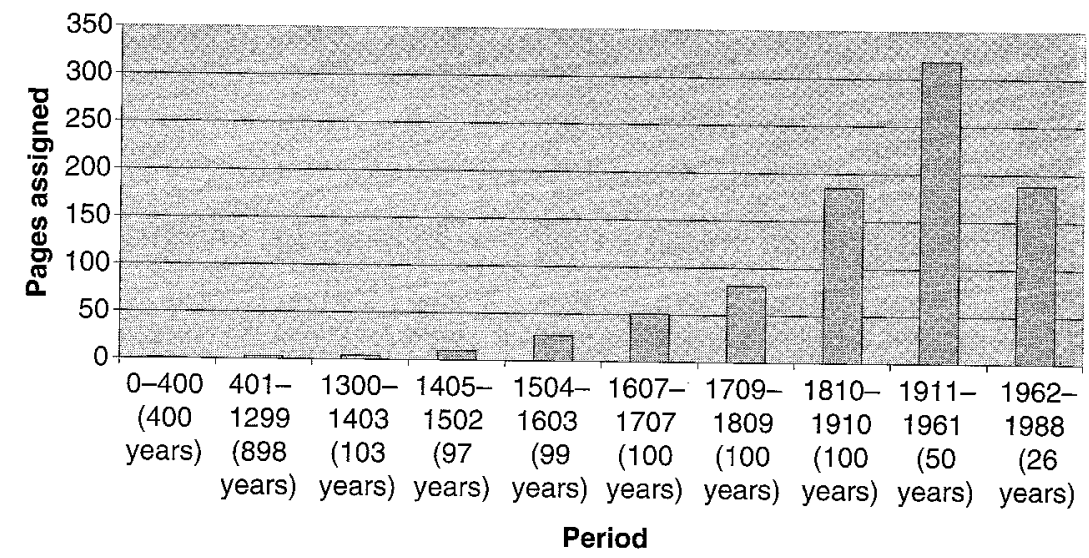

Fig. 4.1. Asimov's chronology of science and discovery. Note that dates $\mathrm{BC}$ have been omitted (Asimov covers 4,000,000 $\mathrm{BC}$ to $\mathrm{AD} 0$ in 60 pages). 
Beyond this utterly optimistic view, there is much research on the impact of these technologies, their advantages, further applications, as well as the challenges and problems they bring about (Sismondo, 2004). On the one hand, there is ongoing sociological and philosophical research on the meaning and impact of these technologies. Terms such as cybernetics, information theory, information technology, semiotics, communication technology, information and communication technology, communication studies, net studies, and many others attest to the variety of approaches available in this area. On the other hand, we are becoming increasingly aware of the challenges and problems. This awareness has led to the quest for a more applied ethics that would guide human actions in fields such as medicine, environmental issues, business, and others.

Relying on Masayuki Ida's terminological suggestion, I would like to consider the process he defines as "borderless net business" and relate this topic to the specific area of higher education (Stedman, 1998). In the field of higher education, terms such as online education, distance education, virtual education, and educational technology confirm the growing importance of new technologies for the development of curricula, testing, learning, research, administration, library information, and peer interaction in university settings. More than simply words, these terms also indicate how the university became definitely borderless, transcending not only the classroom and limits of its own campus, but also going beyond national borders by using satellites, Internet connections, television networks, and other recent technological capabilities. Moreover, they also indicate how universities have been more and more intertwined with business practices, requirements, and structures. Also here, ethical and moral questions arise.

A few questions seem to remain open and unanswered amidst the plethora of initiatives that are characterized as proper of the growing field that could be called "borderless net educational business," in which we all - participants in this specific event on borderless net business - are directly or indirectly involved. Our involvement in this field opens us up to a series of questions, but I would like to focus on a few only: What are the values guiding the application of technology to the seemingly natural process of communication? What happens when natural interactions are mediated by layers of apparatuses, networks, businesses, structures, codes, and anonymity that come along with the use of these technologies? What is the positive impact these initiatives may bring about in higher education?

\section{The Problem}

The advent of technological devices is not new. As a matter of fact, technology is a mark of the human civilization process. Thus, the discovery of fire, use of the stone for hunting purposes, development of forks, knives, and chopsticks, as well the advent of printing and the invention of the automobile are all examples in what we define as history of technology. We certainly use these technological devices 
every day and take them for granted, without reflecting very much on their use or questioning their application in domestic life. What is the problem of applying new technology to higher education?

We may present a series of suggestions as to what the problem may be. In ancient Greece, Plato was already questioning those groups that considered technology [techne] more important than reason $[\log o s]$. Descartes defined the human body as a mechanical machine. In 20th century Germany, Martin Heidegger discussed the pervasive influence of Technik (Heidegger 1953; see also Dreyfus 1979) while Adorno researched the dangers of what he called the "cultural industry" in the United States [Kulturindustrie] (1947). More recently. Jacques Ellul argued that science became enslaved by technology (Ellul 1972), while Donna Haraway showed that technology has changed the very way we define humans (2004).

Following these authors, we can see the advent of individualism, capitalism, colonialism, militarism, sexism, consumerism and other modern ideologies as the values guiding the use of recent technologies (Erickson 2005). Most contemporary technologies for broadcasting and information, for instance, resulted from military research during the 20th century. The National-Socialist dictatorship in Germany invested heavily in telecommunications. The Manhattan Project in the United States required the development of enciphered telecommunication. Similarly, current anti-terrorist initiatives by several governments include wiretapping, eavesdropping, and other intelligence activities based on the many times illegal search of private citizens' information. One of the big challenges today is not only the danger of authoritarian and military governments using available network technologies to contradict civil liberties and privacy, but also the use of these same techniques by civil groups with criminal purposes (Krug, 2005).

As result, there is now the quest for new ethical values to orient a public and private use of network information and communication technologies. Today there is both a need and an opportunity to reconsider which values can address new global situations, contexts and models that are influenced by borderless network information and communication technologies. The field of higher education is not immune from these challenges. All this has led to the need for an ethics for the computer sciences, information studies, and Internet usage in telecommunication (see Floridi 1999). Nevertheless, there are key elements of our communication practices that should not be forgotten as we try to develop an ethics for borderless net business. The communication ethics developed by Karl-Otto Apel can be an important guide in this regard.

\section{An Ideal Ethics of Borderless or Unlimited Communication}

Karl-Otto Apel is a German philosopher who pursues a transformation of Kant's transcendental philosophy and deontological ethics by emphasizing the importance of community relations. To achieve this goal, he reinterprets Kant's theoretical philosophy by means of a turn to language, 
hermeneutics, pragmatics, and semiotics (Apel 1994). According to Apel, the language of our communities provides us already with a medium for a reflection on the very conditions of knowledge, culture, science, and technology. Based on the philosophy of Charles Sanders Peirce, Apel goes as far as to say that science presupposes a community whose members are constantly submitting themselves to review and verification (Apel 1981). This occurs according to a process of argumentation that presupposes a wider normative context. This normative requirement leads us to his discourse ethics.

In 1973, in one of his first papers on ethics, entitled "Das Apriori der Kommunikationsgemeinschaft und die Grundlagen der Ethik", he denounces the pervasive impact of technology at the end of the 20th century and goes "from Kant to Peirce" in order to define a new principle for ethics. He speaks of the a priori of an intersubjective interaction of real human beings projected towards the future in an "ideal unlimited community of communication" [unbegrenzte Kommunikationsgemeinschaft] (Apel 1994:231-253). This idea can surely be related to our discussion on borderless processes enabled by the Internet. What does he mean by "unlimited community of communication"?

In his view, the 20th century witnessed the encompassing impact of technology in our daily lives. I guess we can call this "borderless." As technological problems became global, Apel realized that we need a global ethics as well. In his view, this global character would be given by the borderless characteristic of communication process. In each encounter we establish with our peers, we not only observe an amplification of the idea of community, but also the progressive awareness of the ethical presuppositions and consequences of a principle of communication that must guide our dialectical relationship with reality. Habermas had arrived at a similar position in his definition of an "ideal speech situation" (1994), but in "Das Apriori der Kommunikationsgemeinschaft und die Grundlagen der Ethik" Apel spells out what was at stake in ethics:

Whoever considers the relation between science and ethics in the modern industrial societies around the world has to face a paradoxal situation. On the one hand, the need for a universal ethics, i.e. one accepted as connecting the whole human society, was never so urgent than in our age of a unified civilization resulting from the technological consequences of science. On the other hand, the philosophical task of a rational justification of a universalizable ethics seems to have never been so difficult or even hopeless than in the age of science; and indeed because in this era the idea of intersubjective validity has been prejudged through science, namely through the scientist idea of a normative neutral or value-free "objectivity" (1973 2:359).

To address this dilemma, he proposes a turn to a sophisticated version of ethics based on the following steps: first, he affirms that even logic and science presuppose ethics, for they rely on the fact that people agree and consistently act based on values such as coherence, truth or verification; second, that the logic-scientific rationality or the scientific institution alone is not sufficient to ground ethics because the aim of science and technology is to objectify reality; third, that we need to add the 
recognition of persons as both subjects (not objects) and co-subjects of an interaction in which we address our needs and raise claims as members of a community of communication (1973 2:397f.). In short, Apel considers that once we recognize we participate in a communication process, we cannot but also recognize that we are already relying on a kind of ethics.

In Diskurs und Verantwortung (1988), he develops this view a bit further as he tries to derive an implicit view of solidarity and responsibility that would expand his ideas on community. In his view, it is not an individual's soliloquy or a particular decision according to the case, but a dialogue and mutual recognition among members of a "real community of communication" that establishes the "ideal unlimited community of communication" which must be the point of departure for a new ethics in the age of science (1988:38f.). This recognition that there are others participating in the same process (even if it is borderless, invisible or geographically distant) is what he defined as the fundamental aspect of an ethics of communication or discourse ethics [Diskursethik].

This is certainly an ethical ideal, but it is based on this ideal that we can observe real practices of borderless communication, such as those that occur through media and telecommunication technologies. The ideal of communication helps us to reveal the gaps that occur in real process of communication, and indicate how far we are from a just, free, symmetric, interactive and emancipated form of communication. The most important point for us, however, is his conclusion that our decision to join this ongoing debate about the ehtics of communication is not a matter of faith or convenient private choice, and much less of ideological preferences, but of collective moral responsibility [Verantwortung]. Discourse Ethics, therefore, proposes the application of both real and ideal communication processes as a way for us to judge the ethical limits of communication technologies.

\section{Borderless or Unlimited Communication in the Practice of Higher Education}

So far we have seen that the scientific development of new technologies of broadcasting, information, and communication has led to new forms of interaction. These new technologies are central to contemporary business, since companies can now operate in a world without borders. With these new technologies we objectify our relationships and many times forget or abstract from the subjects or persons with which we interact. This process of abstracting from personal and collective relationships opens the door to a series of manipulations and exploitation. These technologies raise, therefore, a series of questions about ethics and responsibility of business, including in those cases in which businesses partner with higher education (Stedman, 1998).

If one of the main problems of borderless technologies is its abstraction from real persons and interactions, a new ethics to cope with this problem could simply propose that we include real persons and real communicative interactions. This is precisely the normative framework that could offer guidance for our actions in this complex field. Recently, however, new debates have emerged on the 
need to stress the very original meaning of the word 'responsibility': to respond to, to be accountable to society. I believe the ethics of communication proposed by Apel can be very useful in this regard because it proposes not only our involvement in real communication and recognition that there are others involved in this process, but also requires that we respond to these other voices - based, of course, on principles such as freedom, respect, justice and symmetry, which seem to disappear in technologically mediated interactions.

Now we need to address the question regarding how this model would apply to us as members of educational institutions affiliated to IAMSCU (2005). As such, we are already part of an international or global network that faces the same challenges mentioned above. If we use information technologies in a borderless perspective, chances are that we are forgetting or abstracting from someone. The challenge here is dual. We need to acknowledge this fact and, once we recognize that there are others hidden in this process, we are forced to answer to them in a different way, beyond the technological ways of excluding and erasing people. How to turn this ideal into reality?

Several theories propose that individuals are the ones to be responsible for concrete application of ethics, as they face moral dilemmas and a reach a personal decision about the best course of action (McIntyre, 1984; Weber, 1959). Applying this line of thought to institutions of higher education, the best we can do is teach traditional virtues and expect that persons apply them in their real lives. Another theoretical approach emphasizes collectivity and the need for normative frameworks and rules that guide individual actions (Manners, 2008). Also here, an institution of higher education would simply follow the guidelines established by the government or an association.

As institutions based on the Wesleyan tradition, the institutions affiliated with IAMSCU can neither expect the infallibility of individual behavior nor rely only on regulations established by governments. Rather, they have to go beyond these markers. Many nations are trying to erect new legal frameworks to cope with the problems related to Internet borderless business, but their tools are very limited when applied beyond the borders of the Nation-State. As a matter of fact, private businesses realized these limits and are trying to go beyond both individual virtuosity and the legal frameworks of given nations (Smucker, 2006). As a result, they are establishing their own ethical codes and guidelines, which would orient them as corporations that transcend national borders and operate within the larger framework of a global market. This is done by means of particular codes for social corporate responsibility. But again, where is the room for higher education in this spectrum, especially of institutions related to IAMSCU?

One way of answering this question could be to recall the Christian tradition of ethics and its commitment to education. The same is valid for the Methodist tradition. Those institutions related to this tradition rely on the fact that the first school founded by John Wesley was not necessarily focused simply on personal salvation and individual holiness, but also social needs, including the needs of poor children in England and the need to "reform the nation" (Best, 1988).

iBiZ2008 Workshop for Net Business Ethics, February 10 and 11, 2008, Honolulu 
Accordingly, many other schools, colleges and universities created in different parts of the world were based on similar values. For instance, several institutions were located in impoverished communities and provided courses that were and hopefully still are meaningful to real people. Other institutions founded in Korea and China focused on women's education, such as the case of Ewha Woman's University, a Methodist-related institution that became world-known for focusing on technology for women. Others emphasized the needs and situation of people of African descent, such as traditional Black colleges in the United States. In Latin America, the Methodist University of Piracicaba has maintained its commitment to providing the basis for democratic efforts in Brazil. And in Africa, the Africa University was established in Zimbabwe and has formed many leaders that have contributed to the search for solutions to problems in Southern Africa, beyond the limits of Zimbabwe.

There is no doubt that these traditions in education can provide a different perspective for ethics and social responsibility, as the practices mentioned above show. They also express their social, environmental and economic concerns, and provide support for public health, poverty reduction, equality, political freedom and education. These practices indicate a different approach to social responsibility, since they are not necessarily based on governmental expedience and pragmatic business maxims, but on ethical principles that transcend these limits. To put it in the language of this workshop: borderless ethical principles. What are these principles? I believed the traditional practices of persons and institutions related to this tradition of education can be expressed in terms of an ethics of communication. This would allow for a communication process that not only discovers them beyond the layers of technological mediation, but also involves people more directly, allowing the involved parts to express themselves and agree upon the topics of discussion and, finally, respond to their needs, concerns, and proposals. I cannot fully explore these issues in this paper. However, there is room for a question: How could we address the challenges of borderless net business in our institutions of higher education with this communicative ethics and responsibility?

\section{Conclusion}

Based on the points mentioned so far, we can attempt to answer the questions above by saying that the practice of concrete borderless communication and interaction among the IAMSCU-related institutions of higher education and the ideal of an ethics of communication as proposed by Apel can be combined if we provide an institutional framework that applies the existing personal, institutional, and technological resources to generate an ongoing borderless communication process. This would be an interesting understanding and application of the "unlimited community of communication."

When we consider the IAMSCU-related institutions of higher education represented in this colloquium, we could use this global network as an opportunity to apply the elements that, according to Apel, represent some of the concrete conditions for a global ethics of communication which, in my 
view, could be applied to borderless situations in business and education. Values such as concern for the whole community, interaction through symmetric relationships, consideration of the rights of disadvantaged people, and others, are compatible with the principles of that movement founded by John Wesley. Based on this tradition, we could argue that the motto "The world is my parish" could already express the motivation for a global movement articulated around a network of institutions in the area of education, which are characterized by their ethics and social responsibility.

All the characteristics mentioned above indicate that important tools for collective action that promote social responsibility are already at place. I believe that establishing frameworks for real communication among the participants in this community is a good principle. I also believe that the workshop iBiZ2008 "Global Technology, Ethics, and Social Responsibility - An Agenda for Interdisciplinary and International Research on Borderless Net Business" is a good step in this direction.

\section{References}

Adorno, Th. \& Horkheimer, M. (1947) Dialektik der Aufklaerung (Frankfurt: Suhrkamp [1997]).

Apel, K.-.O (1973) Transformation der Philosophie (Frankfurt: Suhrkamp).

--- (1981) Der Denkweg von C.S. Peirce (Frankfurt: Suhrkamp).

--- (1988) Diskurs und Verantwortung (Frankfurt: Suhrkamp).

--- (1994) Selected Essays (Atlantic Highlands: Humanities).

Best, G. (1988) Wesley and Kingswood: 1738-1988 (Bridgwater, Bigwood \& Staple Ltd).

Dreyfus, H. (1979) What Computers Can't Do: The Limits of Artificial Intelligence (New York: Harper \& Row).

Ellul, J. (1972) The Technological Society (New York: Alfred Knopf).

Erikson, M. (2005) Science, Culture and Society (Cambridge: Polity).

Floridi, L. (1999) Philosophy and Computing: An Introduction (London: Routledge).

Habermas, J. (1994) Vorstudien und Ergänzungen zur Theorie des kommunikativen Handelns (Frankfurt, Suhrkamp)

Haraway, D. (2004) The Haraway Reader (New York: Routledge).

Heidegger, M. (1953) Die Frage nach der Technik” in Vorträge und Aufsätze (Pfullingen: Neske, 1954)

IAMSCU (2005) 2005 Directory. The International Association of Methodist-related Schools, Colleges, and Universities (Nashville: GBHEM). 
Krug, G. (2005) Communication, Technology, and Cultural Change (London: SAGE).

Manners, I. (2008) “The normative Ethics of the European Union” in International Affairs, Vol. 84/1, pp. $45-60$.

McIntyre, A. (1984) After Virtue: A Study in Moral Theory (Notre Dame, IN: Notre Dame University Press).

Sismondo, S. (2004) An Introduction to Science and Technology Studies (Malden, MA: Blackwell).

Smucker, J. (2006) "Pursuing Corporate Social Responsibility in Changing Institutional Fields" in Bird, F. \& Velasquez, M. (Eds.) Just Business Practices in a Diverse and Developing World (New York: Palgrave).

Stedman, L. (1998) "New Media and Borderless Education: A Review of the Convergence Between Global Media Networks and Higher Education Providers" in The Technology Source Archives at the University of North Carolina, July 1998 (http://technologysource.org/article/new_media_and_borderless_education/ accessed in March 3, 2008)

Weber, M. (1958) The Protestant Ethic and the Spirit of Capitalism (New York: Scribner \& Sons).

Amos Nascimento studied music, social sciences, and philosophy in Argentina, Brazil, the United States, and Germany, where he obtained his PhD at the University of Frankfurt. He studied with KarlOtto Apel, Juergen Habermas, and Enrique Dussel. He has worked at UMESP, University of Frankfurt, UNIMEP, and is now at the University of Washington. He has participated in conferences and been guest lecturer in many countries. He has published Grenzen der Moderne (1997), A Matter of Discourse: Community and Communication in Contemporary Philosophies (1998), Brasil: Perspectivas Internacionais (2002), Rationalität, Ästhetik und Gemeinschaft (2002) and several articles in Portuguese, Spanish, English, and German focusing on theoretical and applied philosophy. He has been involved with IAMSCU and the World Methodist Council as Chair of the Education Committee, having chaired events and workshops in various countries. 